\title{
Locuciones entre el árabe y el español: desafíos de traducción
}

\section{Chicago y El Club Automóvil de Egipto de Alaa Al Aswany(*)}

\author{
Supervised by: \\ Dra. Manar Abd El Moez \\ Dra. Yasmin Hosny \\ Facultad de Letras \\ Universidad de El Cairo
}

Saafan Amer Saafan

\section{Profesor Asistente de Linguistica Española-Facultad de Lenguas- Universidad de MSA}

\section{Resumen}

Las unidades fraseológicas, entre ellas las locuciones se consideran un patrimonio cultural propio de cada lengua. Por eso, el tema de pasar este legado de una lengua a otra es un trabajo desafiante para cualquier traductor literario. La competencia lingüística y cultural de la persona que lleva esta misión es imprescindible por la peculiaridad de este tipo de combinaciones fijas. En nuestro trabajo, hablamos de los retos de la traducción de las locuciones entre el árabe y el español.

Utilizar las locuciones en la escritura es una buena señal de la competencia lingüística y retórica de los escritores en el campo de la creación literaria. Al momento de intentar pasar este tipo de las unidades fraseológicas de una lengua a otra surgen unos retos para los traductores por la naturaleza lingüística y semántica de estas unidades.

El trabajo se divide en dos partes: la primera parte es teórica; y la segunda es aplicada. En la primera parte, hablamos de las locuciones: su concepto, sus características y sus diferentes clasificaciones. Además, abordamos el tema de la traducción de las locuciones, y las técnicas utilizadas para traducir este tipo de las unidades fraseológicas del árabe al español.

En la segunda parte, analizamos las locuciones sacadas de la novelas:

(*) Locuciones entre el árabe y el español: desafíos de traducción Chicago y El Club Automóvil de Egipto de Alaa Al Aswany, Vol. 10, Issue No.1, Juanary 2021, pp.109-129. 
Deseos de ser egipcio y El club Automóvil de Egipto de Alaa Al Aswany que han sido traducidas al español, comparando las unidades fraseológicas encontradas en el texto original con sus correspondientes en el texto traducido analizando las técnicas que ha empleado el traductor.

Finalizamos el trabajo con las conclusiones sacadas del análisis hecho, y que pueden ser una base para los estudios posteriores en el mismo campo.

\section{Palabras clave}

locuciones-unidades fraseológicas-traducción

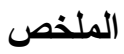

تعتبر التجمعات اللفظية ومن بينها المنصاحبات اللغوية موروث نقافي يميز لغة عن

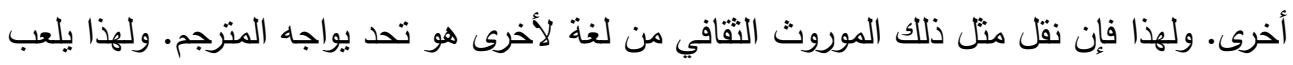

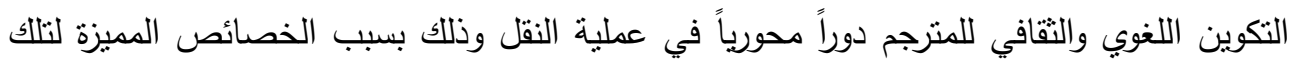
التجمعات اللفظية. سنتتاول في هذا البحث التحديات التي تعترض المترجم أثناء نقل المتصاحبات اللغوية من العربية إلى الإسبانية.

يعتبر استخدام المنصاحبات اللغوية علامة على القدرة اللغوية والأدبية للكاتب. ولكن عند محاولة نقل هذا النوع من التجمعات اللفظية تظهر بعض التحديات أمام المترجم بسبب الطبيعة اللغوية والدلالية لتلاك التجمعات اللفظية.

وينقسم البحث إلى جزئين أساسيين: الأول نظري والثاني نطبيقي. وينتاول الجزء الأول الحديث عن المتصاحبات اللغوية، خصائصها وتصنيفاتها المختلفة. هذا بالإضافة لدراسة الإنيات العلاقة

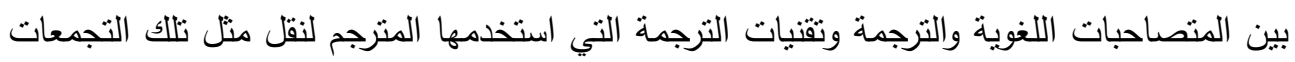
من العربية إلى الإسبانية.

ويشمل الجزء الثاني من البحث تحليل بعض من هذه التجمعات اللفظية المأخوذة من

روايتي نيران صديقة ونادي السيارات لعلاء الأسواني وذلك لمقارنة المتصاحبات اللغوية في العربية

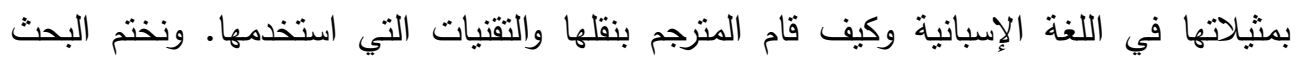
بالملاحظات التي توصلنا إليها والتي من المكن أن تكون قاعدة لدراسات لاحقة في نفس المجال. 


\section{الكلمات المفتاحية \\ التجمعات اللفظية-المتصاحبات اللغوية -الترجمة}

\section{Introducción}

El uso de las locuciones en cada lengua se considera como una aportación única e incomparable de dicha lengua, es que este tipo de combinaciones siempre está atado estrechamente con el patrimonio cultural de cada comunidad lingüística. La connotación metafórica de las locuciones es el factor que las hace peculiar, es que por este motivo el significado de estas combinaciones es el total, y no el aislado de sus constituyentes. Por eso, podemos llegar al fin que son unos bloques culturales peculiares que llevan una metáfora en su entorno.

\section{Locuciones: definición, características y clasificaciones}

Podemos decir que la locución es una combinación de dos componentes que gozan de un alto grado de fijación interna. El significado de esta combinación no surge de la totalidad de sus vocablos de una forma aislada, sino de por totalidad idiomática de sus constituyentes arraigada en el habla de una comunidad lingüística. Las locuciones para Corpas Pastor son ese tipo de combinaciones fijas que se caracterizan por su "fijación interna y unidad de significado". Por eso, estas unidades léxicas no se consideran como enunciados saturados, sino que unos "elementos oracionales" que lleva una carga semántica que las distingue de otras combinaciones fijas. (Corpas Pastor, 1996, p.88)

El uso repetitivo de una locución por los hablantes de una comunidad exige en la mayoría de los casos un grado de fijación de uso y un acuerdo tácito de usar dicha unidad en unas situaciones predeterminadas para expresar un significado específico. Por eso, para reconocer una locución, hay que tener en cuenta el grado de fijación, el significado total no de los componentes aislados y el plano metafórico en cuanto a su significado establecido por los hablantes de una secta linguiística. Así, podemos concluir que la fijación y la idiomaticidad se consideran como los dos bloques grandes sobre los cuales se basan las locuciones. 
Por eso, basándose en el carácter idiomático y las investigaciones realizadas en este campo de unos lingüistas como Corpas Pastor, GarcíaPage y Zuluaga, podemos concluir que las características esenciales de las locuciones son las siguientes: la idiomaticidad, la reinterpretación, la opacidad, la metaforicidad, la fijación, la institucionalización, la capacidad combinatoria y la pluriverbalidad.

En cuanto a las clasificaciones de las locuciones, hay muchas clasificaciones propuestas a manos de los lingüistas en este campo de fraseología. Entre las propuestas destacadas y que han servido como un modelo para las clasificaciones posteriores es la de Julio Casares quien divide las locuciones en: nominales, adjetivales, verbales, participales, adverbiales, pronominales, exclamativas, conjuntivas y prepositivas. Esta taxonomía se considera muy importante por ser la primera que intenta clasificar este tipo de unidades fraseológicas, además se sirve, como lo hemos mencionado antes, de guía para todos los investigadores en este campo de fraseología. (Casares, 1950, p.54)

García-Page afirma que las clasificaciones existentes de las locuciones no son iguales por los diferentes criterios adaptados por los investigadores al proponer sus taxonomías. Su clasificación divide las locuciones en: nominales, adjetivas, adverbiales, prepositivas, conjuntivas, verbales y las locuciones oracionales. (García-Page, 2008, p.55)

A pesar de estas taxonomías, vamos a seguir la clasificación propuesta por Gloria Corpas Pastor, porque es la más flexible de las taxonomías existentes, al lado de ser la más desarrollado incluyendo al mismo tiempo todas las categorías. El criterio por el que la autora clasifica este tipo de combinaciones es su función oracional que está relacionada estrechamente con el significado total y metafórico de los constituyentes de esta unidad fraseológica. La autora divide las locuciones en: (Corpas Pastor, 1996, p.95-112)

1. Locuciones nominales: que se componen por sintagmas nominales que pueden ser: 

a. Sus+adj
b. Sus+prep+sus
c. Sustsus

2. Locuciones adjetivales: la esencia de este tipo de locuciones es un adjetivo complejo que da la misma connotación de una oración compuesta por un atributo y un predicado. Estas locuciones se pueden componer de:
a. Adj+prep+sus
b. Adj+advb+sus
c. Pronombre relativo+adj
d. Prep+adj+sus

3. Locuciones adverbiales: este tipo de locuciones en la mayoría de los casos se componen de unos sintagmas prepositivas, entre ellas:
a. De modo
b. De cantidad
c. De espacio
d. De tiempo
e. Sust+adverb
f. Adj+adverb

4. Locuciones verbales: aquí encontramos las locuciones que tiene un verbo como el núcleo, por eso son las que presentan una variedad a nivel morfosintáctico, entre ellas encontramos estas locuciones compuestas por:
a. V+sus
b. V+complemento
c. Verbo+prep+patricula

5. Locuciones prepositivas: esta categoría de locuciones incluyen las unidades que se componen por un adverbio o una preposición seguidos por los mismos.

6. Locuciones conjuntivas: este tipo de locuciones incluyen las unidades que no se forman por sí mismas. Por eso, se subdividen en dos tipos: subordinantes y coordinantes.

7. Locuciones clausales: incluyen todas las locuciones que expresa una 
preposición, por eso siempre provienen de esta fórmula de sujeto y predicado.

\section{Desafíos de traducir las locuciones}

La traducción de las locuciones en un contexto literario no es una tarea nada fácil, porque el sentido metafórico y general de dichas unidades no se puede descontar de sus constituyentes de una forma separada. Esta dificultad siempre es un resultado del carácter idiomático que es la característica esencial de las locuciones. Por eso, el sentido retorico no se puede deducir de la comprensión literal de los términos de estas unidades fraseológicas. Algunos investigadores en el campo fraseológico afirman que muchas de estas unidades no se pueden traducir, porque están relacionadas con la cultura de una comunidad hablada; por eso puede resultar difícil para una persona no nativa comprenderlas correctamente y reproducirlas de una forma u otra. (Isabel Santa María, 1998, p.302)

El desafío existe en llegar a tener un equivalente adecuado que da el mismo sentido metafórico, porque este paso requiere un alto grado de competencia lingüística y cultural por parte del traductor. En algunos casos, no se puede llegar a tener ese equivalente que da el mismo sentido de una locución, por eso es aceptable para un traductor recurrir a los grados de equivalencia semántica para no dejar espacio en el texto que puede causar una mala interpretación del texto entero. Así, la equivalencia no tiene que ser total, porque esto es tan fácil debido a la naturaleza de estas unidades; pero puede ser también parcial o nula que expresan al fin el significado del contexto de donde vienen. (Sevilla Muñoz, 1997, p.439)

\section{Análisis del corpus}

Vamos a analizar ejemplos de las locuciones extraídas de las novelas Deseos de ser egipcio y El Club Automóvil de Egipto de Alaa Al Aswany según el grado de equivalencia semántica sea total, parcial o nula.

\section{Casos de equivalencia total}

Este grado de equivalencia se da cuando tanto la unidad fraseológica 
de la lengua de origen como la de la lengua meta presentan el mismo significado denotativo y connotativo, la misma base metafórica, la misma distribución y frecuencia de uso, las mismas implicaturas convencionales, la misma carga pragmática y similares restricciones diastráticas, diafásicas y diatópicas. (Corpas Pastor, 2003, p. 217)

\subsection{Deseos de ser egipcio}

\begin{tabular}{|c|c|}
\hline TT & TO \\
\hline Día y noche p.28 & 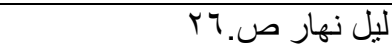 \\
\hline Conseguir el pan p.52 & أكل عبش ص.ی ؟ \\
\hline !Estás como un toro! p.59 & ما أنت زي البمب أهوه ص. ؟0 \\
\hline De golpe p.150 & في أن واحد ص. • ؛ إ \\
\hline Emprendió a golpes p.159 & انهالت ضرباته ص. Vミا \\
\hline Parecía abatida p.176 & غارقة في الحزن ص. بآ1 \\
\hline La sangre me hervía en las venas p.182 & دمى بيفور ص.179 \\
\hline Mientras nos queda una gota de aliento p.203 & مادام فينا نفس ص. INV \\
\hline
\end{tabular}

El traductor ha transmitido la locución en árabe ليل نهار a su equivalente en español "día y noche". La locución en árabe y en español tiene el mismo significado semántico, así la mima metáfora para expresar la continuidad de una cosa. Esta unidad fraseológica se utiliza en un contexto de manifestar un grado tan alto de prolongación de un suceso o de una acción repetitiva sin fin o para siempre.

La unidad fraseológica en árabe أكل عيش no expresa el significado aislado de cada uno de sus componentes para expresar que alguien quiere comer, sino la totalidad de los términos de la locución tiene una imagen retorica para expresar que una persona quiere trabajar para poder vivir. El traductor ha usado un equivalente en español "conseguir el pan" que da la misma connotación semántica y metafórica de querer trabajar para poder ganar dinero. Esta locución en la cultura árabe a veces puede ser un signo de humillación de una persona hacia las condiciones difíciles que están 
alrededor, por eso en algunos casos se utiliza en el contexto de querer pasar los días viviendo en paz dejando todo detrás de la espalda.

La locución en árabe ما أنت زي البمب أهوه se utiliza en un contexto para mostrar que una persona tiene muy buena salud. También, se puede usar en el contexto de animar a una persona para superar una crisis sanitaria. El traductor ha utilizado un equivalente en español" estar como un toro" que da la misma connotación semántica de la locución en árabe. El uso de los sustantivos بع árabe y "toro" en español da la misma metáfora de ser una persona muy sana y muy fuerte.

La locución en árabe في أن واحد se ha transmitido a su equivalente en español "de golpe" que es una locución adverbial. La locución en las dos lenguas tiene el mismo significado semántico donde se utiliza en un contexto para manifestar que una cosa ha pasado de forma súbita y de una vez sin ninguna preparación y sin tener tiempo de tomar cualquier medida para evitarla.

El traductor ha transmitido la locución en árabe انهالت ضرباته a su equivalente en español "Emprendió a golpes" que es una locución verbal que se utiliza en un contexto coloquial. La locución en las dos lenguas se utiliza en un contexto cuando una persona acomete a otra. El verbo en árabe se utiliza también en un contexto cuando se habla de una cosa que se cae de una forma súbita. Por eso, su uso con el sustantivo "golpes" muestra que la acción es un poco violenta y de una vez.

La locución en árabe غارقة في الحزن tiene una connotación metafórica para expresar la profunda tristeza que absorbe a una persona. El traductor ha transmitido la unidad a un equivalente en español "aparecía abatida", que tiene la misma referencia semántica y metafórica. La unidad fraseológica en las dos lenguas se utiliza en el mismo contexto de referir a una persona que se parece muy apesadumbrada por una situación muy difícil que le apodera del todo. La metáfora que da el sustantivo غارق en árabe y "abatido" en español muestra un alto grado de decadencia y desesperación que llega hasta perder el mínimo ápice de ánimo. 
El traductor ha transmitido la locución en árabe دمي بيفور a un equivalente en español "la sangre me hervía en las venas", que es una locución verbal que se utiliza en un contexto coloquial. La locución en las dos lenguas tiene la misma referencia semántica, así mismo la misma imagen retórica. La locución se utiliza normalmente en el contexto de expresar el volumen de enfado producido como una reacción de una persona hacia otra o hacia una situación que puede controlar. El uso del verbo "hervir" que se utiliza sólo con el agua da el cargo metafórico expresando un cierto grado de exageración para demostrar la irritación que apodera a una persona en una situación fastidiosa.

La unidad fraseológica en árabe مادام فينا نفس es una locución que se utiliza siempre en un contexto de animar a alguien o indicar un alto grado de persistencia para realizar una meta. El uso del verbo "quedar" con el sustantivo "aliento" es la esencia de la implicación metafórica y semántica de la unidad, es que es una referencia de determinación y gran voluntad. El traductor ha trasmitido la unidad de forma literal usando eta técnica de traducción literaria. A pesar del sentido literal de la traducción en español, la implicación que lleva la unidad en el TO sigue siendo comprensible para el lector español.

\subsection{El Club Automóvil de Egipto}

\begin{tabular}{|c|c|}
\hline TT & TO \\
\hline De cuando en cuando p.60 & بين الحين والأخر ص.^^ج \\
\hline Las aguas volvieron a su cauce p.72 & تعود المياه لمجاريها ص. بN \\
\hline Se te sale el dinero por las orejas $p .80$ & ما الفلوس على قلبك ص. 19 \\
\hline De vez en cuando p.155 & 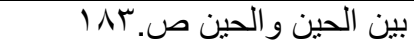 \\
\hline Con un corazón de acero p.334 & قلبه ميت ص. إ؛ \\
\hline Qué se vayan al infierno p.500 & يروحوا في ستين داهية ص. بrآ \\
\hline A merced del viento p.174 & في مهب الريح ص. + 'T \\
\hline Al instante p.218 & أول بأول ص.بrTr \\
\hline
\end{tabular}

El traductor ha transmitido la locución en árabe بين الحين والأخر a su 
equivalente en español "de cuando en cuando". La locución en las dos lenguas es una locución adverbial que tiene la misma referencia semántica, y se utiliza en un contexto para referir a un hábito o a una cosa que se hace algunas veces o de un periodo a otro.

El traductor ha transmitido la unidad fraseológica en árabe تعود المياه ل لججاريها a su equivalente es español que lleva las mismas connotaciones semánticas y metafóricas "Las aguas volvieron a su cauce". El significado literal de la locución en las dos lenguas no tiene nada que ver con el significado total y retorico de la misma. Es que, esta unidad fraseológica se utiliza en un contexto coloquial para aclarar que todo ya está bien en un asunto o en otro contexto para indicar que dos personas ya han vuelto a ser como antes después de pasar por mala racha.

La unidad fraseológica en árabe ما الفلوس على قلبك es una locución que tiene un plano metafórico, es que no hay relación entre el dinero y el corazón. La locución se utiliza en un contexto para referir a una categoría de personas que tienen mucho dinero, pero al mismo tiempo son muy económicos. El traductor ha utilizado un equivalente en español que tiene la misma implicación semántica y metafórica dando la misma imagen retórica de tener un dineral. El equivalente utilizado "Se te sale el dinero por las orejas "es una locución verbal que se utiliza también en un contexto coloquial como un toque de mostrar la sorpresa de alguien hacia la reacción tacaña de una persona adinerada.

El traductor ha transmitido la locución en árabe بين الحين والحين a su equivalente en español "de vez en cuando". La locución en las dos lenguas es una locución adverbial que tiene la misma referencia semántica, y se utiliza en un contexto para referir a una cosa que se hace algunas veces o de tiempo en tiempo y no de una forma regular.

La unidad fraseológica en árabe قلبه ميت es una metáfora que se usa para referir a una persona que no tiene miedo de nada ni de nadie. Siempre se utiliza para elogiar a una persona que echa la mano al fuego. El traductor ha utilizado un equivalente "con un corazón de acero" que da la misma 
connotación semántica, al lado de la misa metáfora de ser hombre de pecho y ser muy valiente. El uso del adjetivo ميث en árabe y el sustantivo "acero" en español para describir el corazón da la misma carga retórica y la misma implicación de ser una persona dura y fuerte.

El traductor ha transmitido la locución en árabe يروحوا في ستين داهية a un equivalente en español "que se vayan al infierno". La locución es las dos lenguas en una locución verbal que se utiliza en un contexto coloquial con la misma implicación semántica y retorica para demostrar el rechazo fuerte y airado hacia una persona que siempre esta importuna y molesta por unas cosas frívolas que no merecen la pena para quedarse enfadado. También, se puede utilizar esta locución en un contexto para demostrar nuestra indiferencia hacia una cosa o una persona para aliviarnos un poco.

El traductor ha transmitido la locución en árabe في مهب الريح a su equivalente en español que tiene la misma connotación semántica y metafórica "a merced del viento". La unidad fraseológica en las dos lenguas es una locución preposicional que se utiliza en un contexto de habla coloquial para mostrar la dependencia de alguien o de lago de una voluntad o fuerza ajena. El uso del sustantivo "viento" tiene un peso semántico en esta unidad, es que da un cierto margen de latos riesgos, porque nadie puede asegurarse de su estado en estas condiciones estando a la espera como salen las cosas, porque no puede controlar la situación.

El traductor ha transmitido la locución en árabe أول بأول a su equivalente en español que lleva la misma implicación semántica "al instante”. La locución en árabe y en español es una locución adverbial que se utiliza en el contexto para aludir a una cosa que se ha realizado al punto sin ningún tipo de dilación.

\section{Casos de equivalencia parcial}

La equivalencia parcial se trata de los equivalentes funcionales donde la base metafórica puede ser distinta, pero al mismo tiempo se conserva el significado conceptual de la unidad. Los equivalentes en este caso tienen una gradación de frecuencia diferente debido a que dependen de unos elementos que no existen en la lengua terminal. En algunos casos, y a 
causa de esas restricciones semánticas, a veces la unidad pierde su carga figurativa. (Corpas Pastor, 2003, p. 209)

2.1.

Deseos de ser egipcio

\begin{tabular}{|c|c|}
\hline TT & TO \\
\hline Ya está, tira de maravilla p.41 & أهي اتعدلت وبقت لوز ص.VT \\
\hline Somos amigos de toda la vida p.212 & عشرة عمر ص.190 \\
\hline Me parece buena persona p.236 & أنا قلبي انفتح للك ص. T ا T \\
\hline $\begin{array}{l}\text { No pienses que soy bobo, y me la vas } \\
\text { a dar con queso p.64 }\end{array}$ & أنا لا كروديا و لا أنا هندي ص.01 \\
\hline
\end{tabular}

La unidad fraseológica en árabe أهي اتعدلت وبقت لوز, es una locución que tiene un sentido metafórico que se utiliza en la mayoría de los casos para expresar que un asunto ha salido muy bien en contrario de las expectativas. El traductor ha utilizado un equivalente en español "de maravilla" que es una locución adverbial que da la misma implicación semántica y metafórica de que una cosa ha salido de una manera exquisita.

La locución en árabe عشرة عمر es una metáfora para mostrar un grado alto de intimidad entre dos o más personas. Esta unidad fraseológica se utiliza siempre en un contexto coloquial para demostrar la relación fuerte, profunda y duradera entre un grupo de personas. El traductor ha utilizado una estructura en español "amigo de toda la vida" para dar el mismo significado semántico de la unidad en árabe.

La unidad fraseológica en árabe أنا قلبي انفتح للك no tiene nada con ver con el significado aislado de sus constituyentes, es que el significado total es una referencia que se utiliza en un contexto para indicar a una persona que ya te sientes relajada al hablar, porque se te parece como una buena persona. El traductor para dar la misma implicación semántica, ha utilizado una locución verbal "ser una buena persona" que demuestra la mismas connotaciones significativas.

La unidad fraseológica en árabe أنا لا كروديا ولا أنا هندي se ha 
transmitido a un equivalente en español que da el mismo significado "no pienses que soy bobo, y me la vas a dar con queso". La unidad en árabe y en español tiene la misma connotación semántica y se utiliza en un contexto para manifestar el rechazo de estar engañado. La metáfora en la locución se basa en el significado total de sus componentes que se utiliza en una situación donde una persona muestra su objeción por los intentos de engaño o burla de los otros.

\subsection{El Club Automóvil de Egipto}

\begin{tabular}{|c|c|}
\hline TT & TO \\
\hline Me dejo el pellejo $p .41$ & أصرف دم قلبي ص.0 \\
\hline Sería una desgracia p.62 & سيكون نهار هم أغبر ص. اY \\
\hline El distinguido p.79 & على سن ورمح ص. • \\
\hline Fue bonito mientras duró p.81 & كان زمان وجبر ص. به9 \\
\hline Le salía el dinero por las orejas p.135 & عنده مال أكتر من الهم على القلب ص. 10V \\
\hline Se os llevaron los demonios p.243 & ساعة شيطان ص. ؟9 ب \\
\hline Se da muchas ínfulas p.262 & على سن ورمح ص.ی آ \\
\hline Yo las pasé canutas p.117 & أنا فحت في الصخر ص. ب؟ा \\
\hline Qué se fastidie p.80 & يروح في ستين داهية ص. 19 \\
\hline
\end{tabular}

La unidad fraseológica en árabe أصرف دم قلبي, es una locución que tiene un plano metafórico para demostrar que alguien ha llegado al límite en una cosa. Esta unidad se utiliza en un contexto coloquial cuando se habla de alguien que no ha dejado ninguna puerta sin tocar para realizar algo. El traductor ha utilizado una locución verbal coloquial en español "me dejo el pellejo" que significa llegar al término de la vida. La connotación semántica en la locución es llegar al término de una cosa sin tener algo más para hacer.

La unidad fraseológica en árabe نهار هم أغبر es una locución que se utiliza en un contexto coloquial como un tipo de amenaza a alguien que ha hecho algo grave, por eso le espera unas consecuencias. El traductor ha 
utilizado el sustantivo "desgracia" en español que se utiliza para aludir a una persona que sufre un suceso doloroso. Las dos unidades aunque no son iguales, pero da la connotación de ser una cosa penosa o áspera.

La locución en árabe على سن ورمح no tiene que ver con su significado aislado de sus componentes, pues el tema de la punta de la lanza es una referencia que se utiliza en un contexto coloquial para aludir que una persona tiene una buena fama y posición entre los otros. La combinación de los componentes de esta unidad da una implicación de superioridad y distinción, es que el uso de la palabra رمح tiene una connotación, porque la lanza siempre esta alta y aparecida. El traductor para da la connotación semántica de la locución en árabe, ha utilizado el adjetivo "distinguido" que se refiere a las personas ilustres.

La locución en árabe كان زمان وجبر se utiliza en un contexto para indicar que una cosa ya no está disponible actualmente como una reacción a los comportamientos de una persona. También, se puede usar como una referencia de llegar al fin de una cosa dando una alusión a una persona de empezar a buscar otra alternativa. El traductor ha utilizado "fue bonito mientras duró" que da la misma implicación semántica de que una cosa ha llegado a su fin y se acabó la fiesta. La locución en árabe se puede usar también como una manera de castigo o de advertencia de una persona para apreciar lo que tiene en la mano.

La unidad fraseológica en árabe أكتر من الهم على القلب es una locución que se utiliza siempre en un contexto coloquial implicando un significado metafórico haciendo una referencia a la abundancia de una cosa, especialmente cuando se habla de dinero. El traductor ha utilizado la expresión idiomática "salirse algo por las orejas" que da la misma implicación semántica de ser una persona con mucho dinero que no puede contar. El uso de unas partes del cuerpo como "corazón" en la unidad en árabe, y "orejas" en la unidad en español dan la misma carga semántica y retórica de la locución.

La unidad fraseológica en árabe ساعة شيطان es una locución que su 
significado total es una referencia metafórica de una situación donde reina la ira y el enloquecimiento. Esta locución siempre se utiliza en un contexto coloquial cuando alguien quiere expresar que su ira se ha acabado y que solo es una mala racha. El traductor ha utilizado un equivalente español "llevarse a alguien el demonio", que es una locución verbal. La unidad en árabe y en español tienen la misma implicación semántica y metafórica en un contexto coloquial para aludir a unos momentos de irritación demasiada.

La unidad fraseológica en árabe على سن ورمح es una locución que se utiliza en un contexto coloquial para referir siempre a una persona distinguida y muy especial. También, se puede usar para aludir a alguien de buena familia como una señal de elogio y orgullo. El traductor, para dar la implicación semántica de la unidad en árabe, ha utilizado el sustantivo "ínfula” con el verbo "dar" para expresar ese nivel de vanidad pretenciosa.

La unidad fraseológica en árabe أكل عيشنا no tiene nada que ver con el significado aislado de sus componentes, es que una locución que se utiliza en un contexto coloquial para referir al trabajo que realiza el hombre para poder vivir. El traductor ha utilizado el equivalente español que da la misma connotación semántica y metafórica "ganar el pan". La locución en las dos lenguas es una alusión al dinero que gana un hombre de su trabajo para poder sobrevivir.

La locución en árabe أنا فحت في الصخر lleva un sentido metafórico lejos del sentido literal de sus componentes. La unidad se utiliza en un contexto para demostrar el tiempo difícil y el sufrimiento que ha vivido alguien para llegar a una cosa. El traductor ha utilizado el equivalente en español "Yo las pasé canutas", es una locución verbal que se emplea normalmente en un contexto coloquial para referir a una persona en una situación muy apurada luchando contra tiempo y haciendo todo el esfuerzo posible para llegar a una meta.

La unidad fraseológica en árabe يروح في ستين داهية, es una locución que se utiliza en un contexto coloquial, y que su significado figurativo no tiene nada que ver con el significado aislado de sus componentes. Esta locución se utiliza en una situación de enojo o fastidio. El traductor ha 
utilizado un equivalente en español "Qué se fastidie" que da las mismas implicaciones semánticas y retoricas, es que es una locución interjectiva coloquial que se utiliza como un comentario relevando alto grado de molestia o enfado.

\section{Casos de equivalencia nula}

La equivalencia nula se encuentra en los casos donde quedan las unidades fraseológicas que no son conceptualizadas en el discurso de la lengua terminal. Este tipo unidades esta siempre atado a unas tradiciones peculiares arraigadas en la cultura del TO. Por ejemplo, todas esas expresiones utilizadas en el campo del toreo en España no tienen equivalentes en otras lenguas. (Corpas Pastor, 2003, p. 209)

3.1. Deseos de ser egipcio

\begin{tabular}{|c|c|}
\hline TT & TO \\
\hline $\begin{array}{l}\text { Vamos, que estamos igual de pobres } \\
\text { que cuando nuestro Señor nos trajo al } \\
\text { mundo p.193 }\end{array}$ & يعني يا مو لاي كما خلقتني ص. V99 \\
\hline $\begin{array}{l}\text { Nadamos en la abundancia y } \\
\text { ahorramos una fortuna p.193 }\end{array}$ & نغرف من الذهب ونكنز ص. V99 \\
\hline Con letras resplandecientes p.203 & تكتب بأحرف من نور ص. IAV \\
\hline
\end{tabular}

La unidad fraseológica en árabe يا مولاي كما خلقتني se utiliza en un contexto coloquial para indicar falta de recursos o pobreza. El uso de la referencia de cuando ser nacido es una implicación de ser una persona sin nada de los pesares mundanos. El traductor no se ha aferrado a usar un equivalente en español para dar las mismas connotaciones semánticas y metafóricas, sin ha traducido la unidad de forma literal. A pesar de eso, el lector puede entender la implicación de la unidad en el TO, porque la traducción literal es clara y comprensible.

La unidad fraseológica en árabe نغرف من الذهب ونكنز es una contradicción de la unidad anterior, es que esa locución se utiliza en el 
contexto coloquial para referir a un tipo de personas que son muy ricos y dependen de muchos recursos económicos. El uso del verbo en árabe نغرف se considera como un intensificador del significado, es que este verbo se utiliza normalmente con la comida al utilizar esas cucharas enormes para servir a alguien un tipo de comida en su plato. El traductor ha transmitido la unidad de una forma literal sin recurrir a un equivalente en su lengua. Por eso, la implicación semántica y metafórica de la unidad en el TO no existe en la traducción hecha.

La unidad fraseológica en árabe تكتب بأحرف من نور es una locución que se utiliza en el contexto de indicar a una cosa muy valiosa o un dicho muy sabio. Por eso, se usa este conjunto del sustantivo "letras" con el adjetivo "resplandeciente" para dar una implicación semántica y metafórica del gran valor y efecto de una cosa. El traductor por no utilizar un equivalente en español, ha recurrido a la técnica de la traducción literaria que ha dado al lector el sentido literal de conjunto fraseológico apartándole al mismo tiempo de la imagen retórica que lleva la unidad en el TO.

\subsection{El Club Automóvil de Egipto}

\begin{tabular}{|c|c|}
\hline TT & TO \\
\hline $\begin{array}{l}\text { Con un rostro descompuesto por la } \\
\text { pena p.71 }\end{array}$ & وجهه مكفهر من الحزن ص.. \\
\hline Ere todo un cañonero p.129 & أنت مدفعجي ص. \\
\hline Tus tiros son envenenados p.129 & شوطك سم ص. 101 \\
\hline Los juicios no tienen fin p.181 & المحاكم حبالها طويلة ص. \\
\hline Quieres un festival de bofetadas p.331 & أنت عاوز جنازة تشبع فيها لطم ص. T + \\
\hline $\begin{array}{l}\text { Mañana lo veremos todo más claro } \\
\text { p.384 }\end{array}$ & الصباح رباح ص..V^乏 \\
\hline El demonio es poderoso p.491 & الثيطان شاطر ص. ابT \\
\hline Sólo cumplíamos órdenes p.162 & أنا عبد المأمور ص. 19 \\
\hline La vas a cagar $p .421$ & حتودينا في داهية ص. OYV \\
\hline
\end{tabular}


La unidad fraseológica en árabe وجهه مكفهر من الحزن es una locución que se utiliza en el contexto para indicar a una persona muy triste. La unidad es una referencia una persona que tiene toda cara muy pálida por la tristeza. El uso del adjetivo en árabe مكفر con el sustantivo "cara" se considera como un intensificador de la implicación semántica y retórica que lleva esta unidad fraseológica, es decir la tristeza que lleva un hombre se ha concentrado en la fisonomía de su cara. El traductor ha transmitido esta esencia retórica con forma literal, pero al mismo tiempo el significado se queda claro.

La unidad fraseológica en árabe أنت مدفعجي se utiliza siempre en un contexto coloquial como una referencia a una persona que juega muy bien, al mismo tiempo es muy rápido. Esta unidad fraseológica tiene una imagen retorica con el uso del sustantivo en árabe مدفع como una referencia de ser una persona ligera y tener un efecto marcador. También, el uso de este sustantivo como adjetivo es un intensificador del poder de alguien. El traductor por mala interpretación de la unidad en el TO, la ha traducido literalmente a "eres un cañonero" que está muy lejos de su valor semántico en la LO. El sustantivo مدفع en árabe es "cañón" en español, pero las implicaciones son diferentes.

El significado retórico de la unidad en árabe شوطك سم no tiene que ver con el significado aislado de sus componentes. Esta locución se utiliza también en un contexto coloquial al momento de jugar futbol para indicar a una persona que marca siempre al gol por sus tiros eficientes. El traductor por mala interpretación de la unidad en el TO, la ha trasladado de forma literal a "tus tiros son envenenados" que no da ningún sentido de su significado real. Por eso, esta traducción puede causar un mal entendimiento por parte del lector español.

La unidad fraseológica en árabe المحاكم حبالها طويلة es una locución que se utiliza siempre en un contexto coloquial en una disputa legal entre dos personas como una alusión a la importancia de ser flexibles y sentarnos juntos para solucionar los problemas sin aferrase a los cortes, porque es un largo camino donde uno puede salir perdiendo. Así, sería mejor negociar 
para llegar a un buen acuerdo. El traductor ha transmitido esta unidad de una forma literal "los juicios no tienen fin" apartando de su connotación semántica y metafórica.

El significado total de la locución en árabe أنت عاوز جنازة تثبع فيها لطم no tiene que ver con el significado aislado de sus componentes. El tema no es de una funeral ni bofetadas, es que esta unidad fraseológica se utiliza en un contexto coloquial como una referencia a ese tipo de personas muy dramáticas, exageradas quien hacen las victimas al momento de pasar por mala racha. El traductor por mala interpretación de la unidad en el texto original, la ha transmitido de una forma literal "quieres un festival de bofetadas" perdiendo de esa forma sus implicaciones semánticas en la cultura del TO.

La locución en árabe الصباح رباح se utiliza en un contexto coloquial como una referencia a un acuerdo tácito entre dos personas para hacer algo, pero lo dejan por ahora hasta que tengan una visión clara después de estudiar todas las posibilidades sobre la tierra. Por eso, se considera como una promesa de reconsiderar algo y pensarlo de nuevo. El traductor ha transmitido esta unidad fraseológica de una forma literal "mañana lo veremos todo más claro" alejando de su alusión semántica en su LO.

El significado literal de la unidad fraseológica en árabe الثيطان شاطر no tiene nada que ver con el demonio, es que se utiliza en un contexto coloquial como una referencia a las malas consecuencias de momentos de ira. En estos momentos, la persona está impulsado por la adrenalina causado por su enojo, así no piensa en lo que hacer no en lo que dice. Por eso, se utiliza esta unidad como una alarma a esa persona para que se calme y pensar lógicamente en lo que va a hacer. El traductor ha transmitido esta unidad vía una traducción literal "el demonio es poderoso", que es un significado literal de los componentes dejando aparte la carga semántica y retórica.

La locución en árabe أنا عبد المأمور tiene un significado total más allá del sentido literal de sus componentes, es que alude a que una persona es un esclavo que obedece las órdenes de superiores. El traductor ha utilizado un 
equivalente en español con la misma connotación semántica "cumplir órdenes", que es una locución verbal. La locución en árabe y en español tiene una implicación de inferioridad del hablante, porque está claro que no tiene ni un margen para reaccionar hacia cualquiera, solo cumple con lo que le asigna.

La unidad fraseológica en árabe حتودينا في داهية, es una locución que lleva una implicación retórica al usar en un contexto coloquial indicando a las consecuencias graves de la decisión de alguien. El traductor ha utilizado el equivalente español que lleva la misma connotación semántica y metafórica "la vas a cagar", que es una locución verbal malsonante, y que se utiliza también en un plano coloquial al cometer un error garrafal y difícil de solucionar.

\section{Conclusión}

Finalmente, ya podemos llegar a revelar la estrecha conexión entre la unidad fraseológica y el contexto donde aparece. Por eso, encontrar un equivalente de una unidad fraseológica de una lengua en otra se considera uno de los mayores retos que enfrenta al traductor literario, especialmente si el tema trata de una unidad que lleva en su entorno un plano metafórico. Algunas veces, el traductor no puede llegar a tener un equivalente total al momento de traducir este tipo de combinaciones. Por eso, no debemos dejar a parte los otros grados de equivalencia sea parcial cuando el equivalente coincide con el sentido, o nula cuando el traductor utiliza la técnica de la traducción literal para trasmitir el significado de la UF. Pero, en la mayoría de los casos, la equivalencia es parcial por la naturaleza del carácter idiomático de este tipo de combinaciones que se caracterizan por la metaforcidad. También, podemos decir que la traducibilidad de las UF no es una tarea fácil, ya que por otro lado su intraducibilidad es una característica suya. 


\section{Bibliografía}

Casares, J. (1950). Introducción a la lexicografía moderna. Madrid: CSIC.

Corpas Pastor, G. (2003). Diez años de investigación en fraseología: análisis sintáctico-semánticos, contrastivos y traductológicos. Frankfurt: Vervuert; Madrid: Iberoamericana.

(1996). Manual de fraseología española. Madrid:

Gredos.

García-Page Sánchez, M. (2008). Introducción a la fraseología española. Estudio de las locuciones. Barcelona: Anthropos.

Santamaría Pérez, I. (1998). El tratamiento de las unidades fraseológicas en la lexicografía bilingüe. ELUA. Estudios de Lingüística, N. 12 (1998); pp. 299-318: Universidad de Alicante. Departamento de Filología Española, Lingüística General y Teoría de la Literatura.

Sevilla Muñoz, J. (1997). Fraseología y traducción. Madrid: Revista Complutense de Estudios Franceses. 